Tohoku J. Exp. Med., 2002, 198, 163-173

\title{
Odor Perception in Patients with Multiple Chemical Sensitivity
}

\author{
Masayuki Ojtma, Hideki Tonori, Toshiniko Sato, Kou Sakabe, ${ }^{1}$ Mikio \\ Miyata, ${ }^{1}$ Satoshi Ishikawa ${ }^{1}$ and Yoshinaru Aizawa \\ Department of Preventive Medicine and Public Health, School of Medicine, \\ Kitasato University, Sagamihara 228-8555, and \\ ${ }^{1}$ Environmental Medical Center, The Kitasato Institute Hospital, Tokyo 108- \\ 8642
}

Ojima, M., Tonori, H., Sato, T., Sakabe, K., Miyata, M., Ishikawa, S. and Auzawa, Y. Odor Perception in Patients with Multiple Chemical Sensitivity. Thohoku J. Exp. Med., 2002, 198 (3), 163-173_ Since symptoms typical for multiple chemical sensitivity (MCS) are induced by exposure to low levels of chemicals, we hypothesize that MCS represents an impaired recognition of odors or an increased emotional reaction to common odors. Twenty-five subjects with MCS, 20 women and 5 men, and 50 gender-and-age matched controls participated in this study. The University of Pennsylvania Smell Identification Test (UPSIT) and the Cross-Cultural Smell Identification Test (CC-SIT) were administered. In addition to selecting the most probable odor among the four, the subjects were asked their impression of each odor. Odor identifiability evaluated by the scores of two tests, were almost equal in MCS and control groups. The mean CC-SIT odor per person with pleasant feeling was lower in MCS than in controls. The mean odor per person creating an unpleasant sensation was higher in MCS than in the controls. Gingerbread was the only odor making MCS subjects more pleasant than the controls. Nine out of 40 UPSIT odors were felt as unpleasant by MCS subjects more than by controls. This study indicates that MCS subjects are able to identify the odors equally as well as the controls but feel unpleasant to a larger number of odors than the controls. Despite unknown mechanisms of the altered odor perception in MCS, the application of these tests for diagnostic procedure of MCS is proposed. ___ odor perception; multiple chemical sensitivity; smell identification test; olfaction; emotional reaction

(C) 2002 Tohoku University Medical Press

Multiple chemical sensitivity (MCS) has become an increasingly frequent diagnosis assigned to patients with symptoms associated with exposure to environmental chemicals (Hummel et al. 1996). MCS patients have symptoms such as fatigue, headache, dizziness,

Received September 25, 2002; revision accepted for publication November 16, 2002.

Address for reprints: Yoshiharu Aizawa, Department of Preventive Medicine and Public Health, Kitasato

University School of Medicine, 1-15-1, Kitasato, Sagamihara 228-8555, Japan.

e-mail: aizawa@kitasato-u.ac.jp 
dysesthesia, blurred vision, memory loss, and lack of concentration, and these complaints are difficult to differentiate from fibromyalgia, chronic fatigue syndrome, and posttraumatic stress disorder. Thus, Cullen (1987) introduced major criteria for definition of MCS that have become the most widely used: MCS is an acquired disorder characterized by recurrent symptoms, referable to multiple organ systems, occurring in response to demonstrable exposure to many chemically unrelated compounds at doses far below those established in the general population to cause harmful effects. No single widely accepted test of physiologic function can be shown to correlate with symptoms (Miller and Mitzel 1995). Proponents of the syndrome propose that a high level of exposure to common environmental chemicals often initiates sensitivity, and chronic lower level exposure perpetuates the problem (Randolph 1970)

To date there are numerous hypotheses regarding MCS etiology, which is a matter of debate (Hummel et al. 1996). These hypotheses include changes of the immune system, neurotoxicity, psychological problems and behavioral conditioning involving psychophysiologic mechanisms (Tonori et al. 2001; Simon et al. 1993). MCS symptomatics claim that they acquired a sensitized state as the result of chemical exposure, usually to formaldehyde, solvents or pesticides. Following sensitization, symptoms increase in number and severity, which over time the MCS symptomatics attribute to various types of exposure which are innocuous to most individuals. Odors might cause either sensitization or elicitation of MCS symptoms, including altered odor sensitivity, primary irritancy or irritancyinduced upper airway reactivity, neurogenic switching of trigeminal irritancy signals, timedependent sensitization and limbic kindling, central nervous system toxicity and various psychiatric conditions.

The basic hypothesis of this present study is that MCS represents an impaired recognition of odors or an increased emotional reactions to common odors. If so, the odor identification test could be the means of a diagnostic procedure and evaluation for severity of MCS.

\section{SubJECTS AND METHODS}

\section{Subjects}

MCS subjects were recruited from patients who visited the Environmental Medical Center, Kitasato Institute Hospital. All subjects were diagnosed as MCS by one of expert physicians making reference to Cullen's criteria (Cullen 1987). Physicians performed a physical examination, excluding the presence of neurological or immunological diseases that might imitate MCS symptoms. Twenty-five patients, 20 women and 5 men, participated in the study. Mean age was $33.8 \pm 8.75$ years (range; $21-50$ years) in women, $37.2 \pm 8.04(28-47)$ in men, $34.5 \pm 8.56$ years $(21-50)$ totally. An overview of the individual patients' characteristics is as follows: $28 \%$ of subjects chiefly complained of skin problems, $20 \%$, respiratory system, $12 \%$, dizziness, and $8 \%$, hyperolfaction, while they all complained of a variety of symptoms. The main place where chemical exposure initiated MCS symptoms was: residence, $28 \%$, workplace, $20 \%$, and in the community, $12 \%$. Only one woman was a current smoker.

A total of 50 controls were gender-and age-matched within 4 years in this study. The mean ages of the female, male, total control subjects were $33.2 \pm 8.65$ years $(21-50), 37.4 \pm$ $7.95(28-50)$ and $34.0 \pm 8.61(21-50)$ respectively. They were clerks and students of Kitasato University. Eleven subjects smoked at the time of examination.

\section{Methods}

Prior to the olfactory examinations, informed consent was obtained and a detailed history of the participants excluded the presence of acute diseases of the upper respiratory tract. Examination of nasal cavity was carried out by rhinoscopy. The University of 
Pennsylvania Smell Identification Test (UPSIT, Sensonics, Inc., Haddon Heights, NJ, USA) was administered in this study. This test consists of four envelope-sized booklets containing 10 odors each, one odor per page. The 'scratch and sniff' stimuli are embedded in microencapsulated crystals located at the bottom of each page. A multiple-choice question with four alternative answers for each item is located immediately above each odor (Doty et al. 1984).

The Cross-Cultural Smell Identification Test (CC-SIT, Sensonics, Inc.), an international version of Smell Identification, consists of 12 odorants (Doty et al. 1996). The tests were carried out by the same procedure as UPSIT.

In addition to selecting the most probable odor among the four items, the subjects were asked their impression of the odor and to choose one of the following: (a) pleasant, (b) unpleasant, (c) neutral, (d) "unable to perceive." If the subjects thought it hardly identify the odorants, they answered (e) "hard to identify." CC-SIT was always administered prior to UPSIT.

\section{Statistical analyses}

Statistical analyses were performed by use of StatView (SAS institute Inc., Cary, NC,
USA). Statistical difference was evaluated by the Student $t$-test, since most variables were distributed normally. Chi-square analysis was used for the two-by-two frequency tables.

\section{RESULTS}

\section{Odor identifiability by UPSIT and CCSIT}

The mean values and standard deviations of scores and percent correctness of UPSIT and CC-SIT are shown in Table 1. No statistical difference was found between MCS and controls in either test. The mean percent scores were not remarkably different between UPSIT and CC-SIT in either the MCS or control group.

Classificaion of olfactory disturbance of MCS revealed almost equal prevalence of each category with the controls as shown in Table 2.

\section{Impression of odors in MCS}

The mean CC-SIT odors per person with a pleasant feeling was lower in all MCS subjects than in the controls as shown in Table $3(p<$ 0.05 ). The mean odor per person creating an unpleasant sensation was higher in all MCS subjects than in the control for both UPSIT $(p<0.05)$ and CC-SIT $(p<0.01)$. Women with MCS showed a higher mean unpleasant odor rate compared with female controls for UPSIT and CC-SIT $(p<0.05)$. The mean UPSIT odor

TABLE 1. Average scores and percentages of correctness in MCS and controls according to gender and smell identification tests

\begin{tabular}{|c|c|c|c|c|c|c|c|}
\hline \multirow{2}{*}{ Tests } & \multirow{2}{*}{ Sex } & \multicolumn{2}{|c|}{ Men } & \multicolumn{2}{|c|}{ Women } & \multicolumn{2}{|c|}{ Total } \\
\hline & & Scores & $\%$ & Scores & $\%$ & Scores & $\%$ \\
\hline \multirow[t]{2}{*}{ UPSIT } & MCS & $\begin{array}{c}30.4 \pm 2.1 \\
(28-30)\end{array}$ & $\begin{array}{c}76.0 \pm 5.4 \\
(70-85)\end{array}$ & $\begin{array}{c}31.3 \pm 3.1 \\
(26-36)\end{array}$ & $\begin{array}{c}78.1 \pm 7.8 \\
(65-90)\end{array}$ & $\begin{array}{c}31.1 \pm 2.9 \\
(26-36)\end{array}$ & $\begin{array}{c}77.7 \pm 7.4 \\
(65-90)\end{array}$ \\
\hline & CONT & $\begin{array}{c}28.8 \pm 3.0 \\
(23-33)\end{array}$ & $\begin{array}{l}72.0 \pm 7.5 \\
(57.5-82.5)\end{array}$ & $\begin{array}{c}31.7 \pm 4.2 \\
(21-39)\end{array}$ & $\begin{array}{c}79.1 \pm 10.6 \\
(52.5-97.5)\end{array}$ & $\begin{array}{c}31.1 \pm 4.1 \\
(21-39)\end{array}$ & $\begin{array}{r}77.7 \pm 10.4 \\
(52.5-97.5)\end{array}$ \\
\hline \multirow[t]{2}{*}{ CC-SIT } & MCS & $\begin{array}{c}9.4 \pm 1.5 \\
(8-12)\end{array}$ & $\begin{array}{l}78.3 \pm 12.6 \\
(66.7-100)\end{array}$ & $\begin{array}{c}9.5 \pm 1.5 \\
(7-12)\end{array}$ & $\begin{array}{l}79.6 \pm 12.5 \\
(58.3-100)\end{array}$ & $\begin{array}{c}9.5 \pm 1.4 \\
(7-12)\end{array}$ & $\begin{array}{l}79.3 \pm 12.3 \\
(58.3-100)\end{array}$ \\
\hline & CONT & $\begin{array}{c}9.2 \pm 1.0 \\
(7-11)\end{array}$ & $\begin{array}{l}76.7 \pm 8.6 \\
(58.3-91.6)\end{array}$ & $\begin{array}{c}9.6 \pm 1.6 \\
(7-12)\end{array}$ & $\begin{array}{l}80.0 \pm 13.6 \\
(58.3-100)\end{array}$ & $\begin{array}{c}9.5 \pm 1.5 \\
(7-12)\end{array}$ & $\begin{array}{l}79.3 \pm 12.7 \\
(58.3-100)\end{array}$ \\
\hline
\end{tabular}

Shown by mean \pm s.D. ( ); range $\operatorname{MCS} ; n=5$ (men), 20 (women) and 25 (total), CONT; $n=10$ (men), 40 (women) and 50 (total), UPSIT; 40 questions CC-SIT; 12 questions. 
TABLE 2. Prevalence of degrees of olfactory impairments in MCS and controls according to gender and smell identification tests

\begin{tabular}{|c|c|c|c|c|c|c|c|}
\hline \multirow{2}{*}{ Tests } & \multirow{2}{*}{ Classification } & \multicolumn{2}{|c|}{ Men } & \multicolumn{2}{|c|}{ Women } & \multicolumn{2}{|c|}{ Total } \\
\hline & & $\overline{\mathrm{MCS}}$ & CONT & MCS & CONT & MCS & CONT \\
\hline \multirow{6}{*}{ UPSIT } & $\begin{array}{c}\text { Normosmia } \\
\text { (M: } 34-40, W: 35-40)\end{array}$ & $1(20.0)$ & $0(0.0)$ & $4(20.0)$ & $9(22.5)$ & $5(20.0)$ & $9(18.0)$ \\
\hline & $\begin{array}{c}\text { Mild Microsmia } \\
\text { (M: } 30-33, \text { W: } 31-34 \text { ) }\end{array}$ & $3(60.0)$ & $5(50.0)$ & $7(35.0)$ & $18(45.0)$ & $10(40.0)$ & $23(46.0)$ \\
\hline & $\begin{array}{l}\text { Moderate Microsmia } \\
\text { (M: } 26-29, \mathrm{~W}: 26-30)\end{array}$ & $1(20.0)$ & $3(30.0)$ & $9(45.0)$ & $9(22.5)$ & $10(40.0)$ & $12(24.0)$ \\
\hline & Severe Microsmia $(19-25)$ & $0(0.0)$ & $2(20.0)$ & $0(0.0)$ & $4(10.0)$ & $0(0.0)$ & $6(12.0)$ \\
\hline & Total Anosmia (6-18) & $0(0.0)$ & $0(0.0)$ & $0(0.0)$ & $0(0.0)$ & $0(0.0)$ & $0(0.0)$ \\
\hline & Probable Malingering (0-5) & $0(0.0)$ & $0(0.0)$ & $0(0.0)$ & $0(0.0)$ & $0(0.0)$ & $0(0.0)$ \\
\hline \multirow{5}{*}{ CC-SIT } & Normal $(8<)$ & $5(100.0)$ & $9(90.0)$ & $17(85.0)$ & $34(85.0)$ & $22(88.0)$ & $43(86.0)$ \\
\hline & Mild Disturbance (7) & $0(0.0)$ & $1(10.0)$ & $3(15.0)$ & $6(15.0)$ & $3(12.0)$ & $7(14.0)$ \\
\hline & Moderate Disturbance (5-6) & $0(0.0)$ & $0(0.0)$ & $0(0.0)$ & $0(0.0)$ & $0(0.0)$ & $0(0.0)$ \\
\hline & Severe Disturbance (4) & $0(0.0)$ & $0(0.0)$ & $0(0.0)$ & $0(0.0)$ & $0(0.0)$ & $0(0.0)$ \\
\hline & Anosmia $(<3)$ & $0(0.0)$ & $0(0.0)$ & $0(0.0)$ & $0(0.0)$ & $0(0.0)$ & $0(0.0)$ \\
\hline
\end{tabular}

( ); range of scores for each category in men (M) and women (W), $n$ ( ); frequency (\%), MCS; $n=5$ (men), 20 (women) and 25 (total). CONT; $n=10$ (men), 40 (women) and 50 (total).

claimed as "not perceived" in MCS was lower than in the controls $(p<0.05)$.

The number of MCS subjects choosing pleasant for one or more odor was significantly lower than that of the controls in CC-SIT ( $p<$ 0.05 ) as shown in Table 4. The number of MCS subjects who claimed "not perceived" for one or more odor was lower than in the controls in UPSIT $(p<0.05)$.
Cut-off points to differentiate MCS from controls Cut-off points of unpleasant odors to differentiate MCS subjects from the controls are shown in Table 5. The mean +2 s.D. appears to be the appropriate cut-off point for UPSIT and CC-SIT: 21 unpleasant odors per person for UPSIT and 6 for CC-SIT.

TABLE 3. Average numbers of odors per person making different impressions

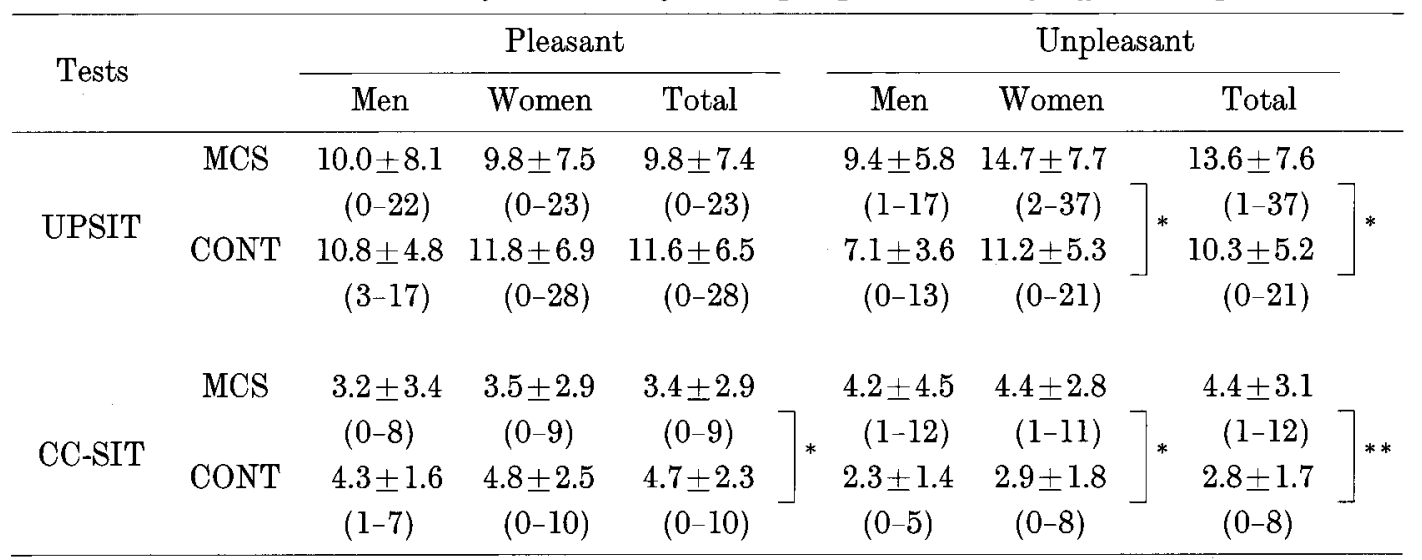

Shown by mean \pm s.D. ( ); range MCS; $n=5$ (men), 20 (women) and 25 (total), ${ }^{*} p<0.05 . \quad{ }^{* *} p<0.01$. 
Impression of odors in MCS according to age groups

Neither the mean number of pleasant UPSIT nor CC-SIT odor per subject in MCS significantly differed from those of the controls in any of the three age groups as shown in Fig. 1. The mean number of CC-SIT unpleasant odors in the MCS group for the age group 30-39 years was higher than that of the controls as shown in Fig. $2(p<0.01)$.

Odors making different esthetic impression for MCS and controls

The odors which created significantly different prevalence of feelings in MCS subjects compared to the controls are listed in Table 6 . The MCS subjects found the odor of gingerbread pleasant more than the controls $(p<0.05)$, while the controls found menthol pleasant more than the MCS subjects $(p<0.05)$. The proportion of MCS subjects who felt unpleasant to UPSIT odors of bubble gum, leather, gasoline, strawberry, peach, grape, soap, rose $(p<0.05)$ or fruit punch $(p<0.01)$ was higher than that of the controls.

The proportion of MCS subjects who selected pleasant for the odors of banana and soap was lower than that of the controls $(p<$ $0.05)$ whereas the proportion of MCS subjects who selected unpleasant for rose, banana, pineapple $(p<0.05)$ or soap $(p<0.01)$ was higher than the controls in CC-SIT.

\section{Correlation between UPSIT and CC-SIT}

The scores of UPSIT and CC-SIT correlate moderately for both MCS $(r=0.62, p<0.001)$ and controls $(r=0.45, p<0.001)$ as shown in Table 7. The slope of the regression line in MCS group tended to be steeper than that of the controls.

The number of UPSIT pleasant odors per person strongly correlate with those of CC-SIT in MCS $(r=0.80, p<0.001)$ and controls $(r=$ $0.73, p<0.001)$. The correlation of unpleasant odors per person in both MCS $(r=0.65, p<$ $0.001)$ and the controls $(r=0.60, p<0.001)$ were moderate between UPSIT and CC-SIT.

\section{DISCUSSION}

A frequent, if not predominant, complaint of persons reporting symptoms of multiple chemical sensitivities is that of heightened sensitivity to smells (Doty et al. 1988). However, thresholds to any odor have been reported not decreased (Doty et al; 1988; Hummel et al. 1996; Fiedler and Kipen 1997; Caccappolo et al. 2000). Although olfactory thresholds of MCS were equivalent to the controls, the MCS group evidenced significantly higher nasal resis-

in MCS and controls according to gender and smell identification tests

\begin{tabular}{|c|c|c|c|c|c|c|c|c|}
\hline \multicolumn{3}{|c|}{ Neutral } & \multicolumn{3}{|c|}{ Not perceived } & \multicolumn{3}{|c|}{ Hard to identify } \\
\hline Men & Women & Total & Men & Women & Total & Men & Women & Total \\
\hline $\begin{array}{c}20.6 \pm 11.1 \\
(9-39)\end{array}$ & $\begin{array}{r}15.3 \pm 6.5 \\
(3-30)\end{array}$ & $\begin{array}{r}16.4 \pm 7.7 \\
(3-39)\end{array}$ & $\begin{array}{l}0 \pm 0 \\
(0-0)\end{array}$ & $\begin{array}{c}0.1 \pm 0.3 \\
(0-1)\end{array}$ & $\begin{array}{c}0.1 \pm 0.3 \\
(0-1)\end{array}$ & $\begin{array}{c}6.4 \pm 4.0 \\
(2-12)\end{array}$ & $\begin{array}{c}4.7 \pm 5.9 \\
(0-20)\end{array}$ & $\begin{array}{r}5.0 \pm 5.5 \\
(0-20)\end{array}$ \\
\hline $\begin{array}{r}21.0 \pm 6.6 \\
(10-32)\end{array}$ & $\begin{array}{r}16.6 \pm 6.5 \\
(5-32)\end{array}$ & $\begin{array}{r}17.5 \pm 6.7 \\
(5-32)\end{array}$ & $\begin{array}{c}1.1 \pm 1.6 \\
(0-5)\end{array}$ & $\begin{array}{c}0.4 \pm 0.8 \\
(0-4)\end{array}$ & $\begin{array}{c}0.5 \pm 1.0 \\
(0-5)\end{array}$ & $\begin{array}{c}7.9 \pm 6.6 \\
(0-20)\end{array}$ & $\begin{array}{c}5.6 \pm 4.6 \\
(0-21)\end{array}$ & $\begin{array}{c}6.0 \pm 5.1 \\
(0-21)\end{array}$ \\
\hline $\begin{array}{c}4.6 \pm 4.3 \\
(0-11)\end{array}$ & $\begin{array}{c}3.9 \pm 2.3 \\
(0-9)\end{array}$ & $\begin{array}{r}4.0 \pm 2.7 \\
(0-11)\end{array}$ & $\begin{array}{l}0 \pm 0 \\
(0-0)\end{array}$ & $\begin{array}{c}0.1 \pm 0.3 \\
(0-1)\end{array}$ & $\begin{array}{c}0.8 \pm 0.2 \\
(0-1)\end{array}$ & $\begin{array}{c}0.4 \pm 0.5 \\
(0-1)\end{array}$ & $\begin{array}{c}0.9 \pm 1.3 \\
(0-4)\end{array}$ & $\begin{array}{c}0.8 \pm 1.2 \\
(0-4)\end{array}$ \\
\hline $\begin{array}{c}5.2 \pm 2.3 \\
(1-9)\end{array}$ & $\begin{array}{c}4.0 \pm 2.6 \\
(0-10)\end{array}$ & $\begin{array}{c}4.2 \pm 2.5 \\
(0-10)\end{array}$ & $\begin{array}{c}0.2 \pm 0.4 \\
(0-1)\end{array}$ & $\begin{array}{c}0.1 \pm 0.3 \\
(0-1)\end{array}$ & $\begin{array}{c}0.1 \pm 0.3 \\
(0-1)\end{array}$ & $\begin{array}{c}1.3 \pm 1.5 \\
(0-4)\end{array}$ & $\begin{array}{c}0.8 \pm 0.8 \\
(0-3)\end{array}$ & $\begin{array}{c}0.9 \pm 1.0 \\
(0-4)\end{array}$ \\
\hline
\end{tabular}

CONT; $n=10$ (men), 40 (women) and 50 (total). 
TABLE 4. Prevalence of MCS and control subjects having an impression against one or more odor

\begin{tabular}{|c|c|c|c|c|c|c|}
\hline Tests & & Pleasant $\geqq 1$ & Unpleasant $\geqq 1$ & Neutral $\geqq 1$ & Not perceived $\geqq 1$ & $\begin{array}{c}\text { Hard to } \\
\text { identify } \geqq 1\end{array}$ \\
\hline \multirow{4}{*}{ UPSIT } & $\operatorname{MCS}(n=25)$ & 21 & 25 & 25 & 2 & 17 \\
\hline & $(\%)$ & (84) & $(100)$ & $(100)$ & (8) $*$ & $(68)$ \\
\hline & CONT $(n=50)$ & 48 & 48 & 50 & $16^{\lrcorner}$ & 43 \\
\hline & $(\%)$ & $(96)$ & $(96)$ & $(100)$ & $(32)$ & $(88)$ \\
\hline \multirow{4}{*}{ CC-SIT } & $\operatorname{MCS}(n=25)$ & 19 & 25 & 23 & 2 & 10 \\
\hline & $(\%)$ & $(76) *$ & $(100)$ & (92) & (8) & $(40)$ \\
\hline & CONT $(n=50)$ & $48^{-}$ & 47 & 48 & 7 & 27 \\
\hline & $(\%)$ & $(96)$ & (94) & (96) & (14) & (54) \\
\hline
\end{tabular}

${ }^{*} p<0.05$.

TABLE 5. The cut-off points of unpleasant odors to differentiate MCS from controls

\begin{tabular}{clccccc}
\hline \multirow{2}{*}{ Tests } & & \multicolumn{5}{c}{ Cut-off point } \\
\cline { 3 - 7 } & & +1 s.D. & +2 s.D. & +2.3 s.D. & +2.7 s.D. & +3 s.D. \\
\hline \multirow{3}{*}{ UPSIT } & Point & 16 & $21^{*}$ & $22^{*}$ & $23^{*}$ & 26 \\
& Sensitivity (\%) & 36.0 & 16.0 & 16.0 & 12.0 & 4.0 \\
& Specificity (\%) & 82.0 & 98.0 & 100.0 & 100.0 & 100.0 \\
& & & & & & 9 \\
\multirow{3}{*}{ CC-SIT } & Point & 5 & $67^{* *}$ & 20.0 & 16.0 & 16.0 \\
& Sensitivity (\%) & 36.0 & 28.0 & 96.0 & 100.0 \\
& Specificity (\%) & 78.0 & 96.0 & 96.0 & 98.0 & \\
\hline
\end{tabular}

${ }^{*} p<0.05 . \quad{ }^{* *} p<0.01$.

tance, respiration rates and Beck Depression Inventory scores after exposure to chemicals (Doty et al. 1988; Doty 1994).

Therefore, we hypothesize that MCS subjects may have emotional response to various odors and fail to identify the odors by this reaction or for other reasons. This study indicates that MCS subjects are able to identify odors equally as well as the controls. On the other hand, MCS subjects, especially women selected 'unpleasant' to more odors than did the controls. This characteristic finding is attributed to sensory changes in olfactory or trigeminal nerves in the airway, time-dependent sensitization and limbic kindling, central nervous toxicity or psychological factors such as conditioning (Bell et al. 1992).

Fiedler and Kipen (1997) found that at suprathreshold concentrations of phenyl ethyl alcohol (PEA), MCS subjects reported significantly more trigeminal symptoms (e.g., burning, stinging) and rated PEA as more unpleasant and unsafe than did the contorols. These differences between MCS and contol groups were not observed for pyridine (PYR), a known unpleasant, trigeminal stimulant. Another study also observed that when exposed to suprathreshold concentrations of PEA, MCS subjects reported significantly more trigeminal symptoms and lower esthetic ratings of PEA (Caccappolo et al. 2000).

Solvent inhalation and other types of exposures may damage the olfactory epithelium. Despite the extraordinary resilience of the olfactory epithelium, one proposed mechanism for diverse chemicals producing MCS symptoms is 


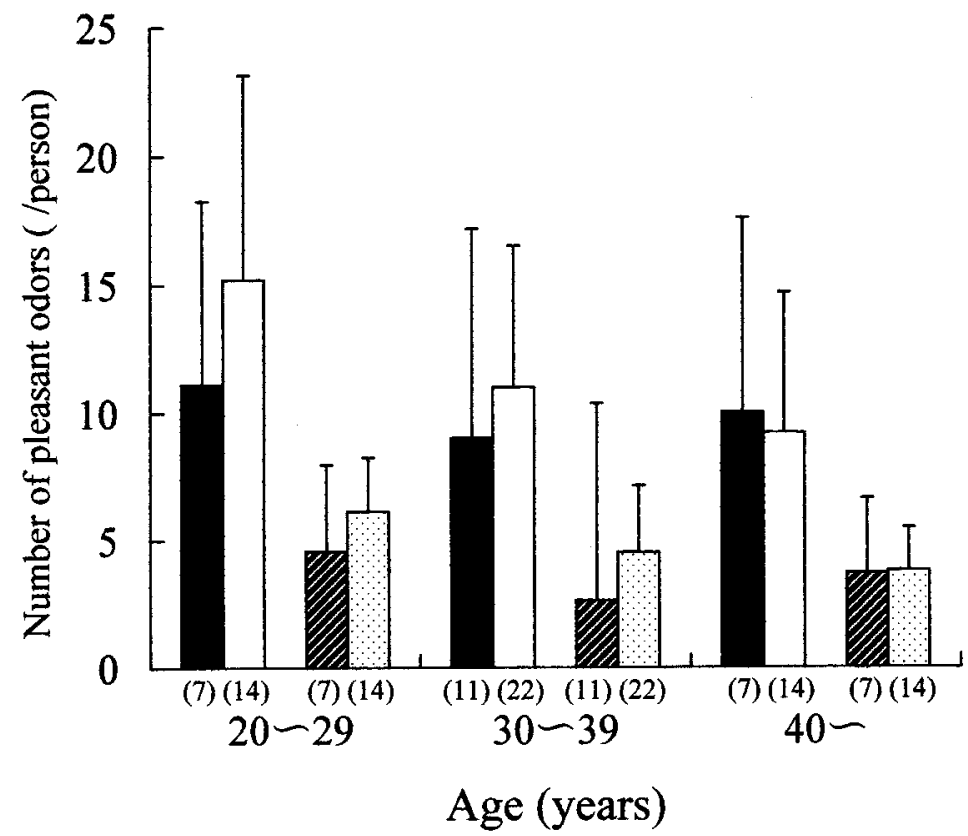

Fig. 1. UPSIT and CC-SIT odors with pleasant feeling per person by age groups.

( ) , n; $\mathbf{\square}$ MCS; $\square$, controls evaluated by UPSIT. 7 , MCS; 3 , controls evaluated by CC: CC-SIT.

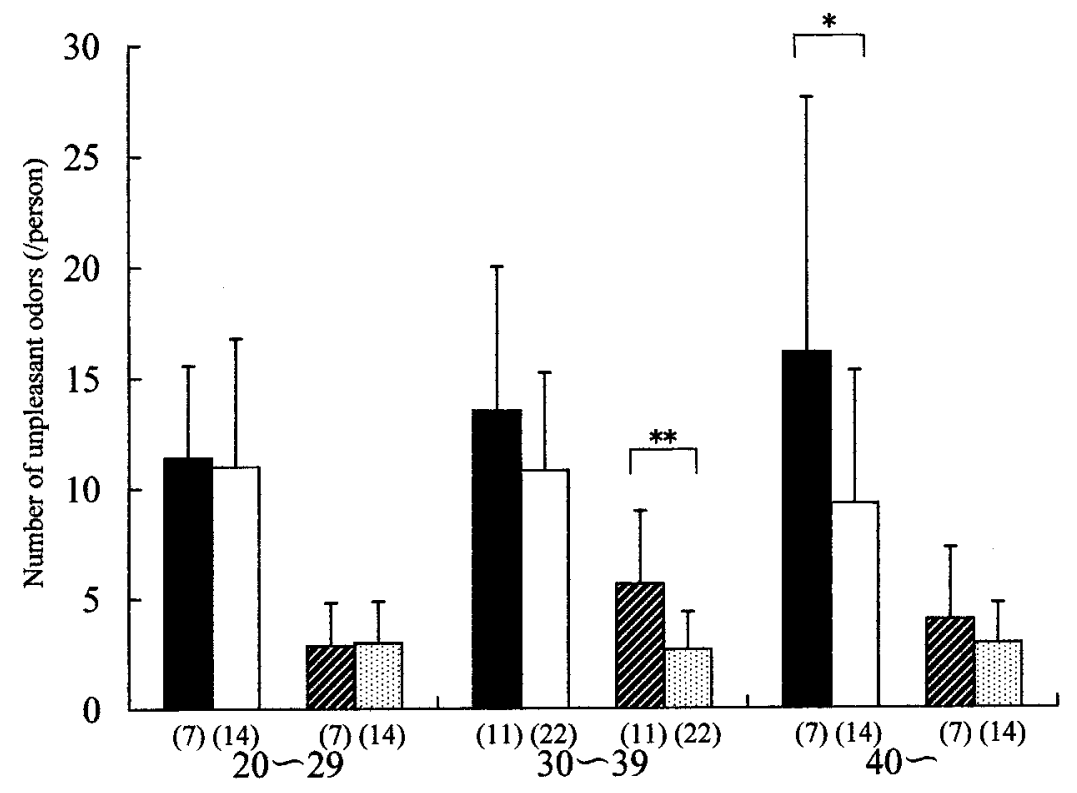

Age (years)

Fig. 2. UPSIT and CC-SIT odors with unpleasant feeling per person by age groups.

( ), $n$; $\mathbf{\square}$ MCS; $\square$, controls evaluated by UPSIT. MCS; 3 , controls evaluated by CC: CC-SIT.

that mucosal damage could lead to a sensitized state through inflammatory mediator release (Ross et al. 1999).
Meggs and Cleveland (1993) observed 10 patients who met Cullen's case definition for the multiple chemical sensitivity syndrome and 
TABLE 6. Odors making significant different esthetic responses between MCS and controls

\begin{tabular}{|c|c|c|c|c|}
\hline Tests & Results & Pleasant & Unpl & \\
\hline \multirow{6}{*}{ UPSIT } & \multirow{5}{*}{$\mathrm{MCS}>\mathrm{CONT}$} & \multirow{5}{*}{ Gingerbread $(32.0)^{*}$} & Bubble gum $(28.0)^{*}$ & Peach $(20.0)^{*}$ \\
\hline & & & Leather $(60.0)^{*}$ & Grape $(16.0)^{*}$ \\
\hline & & & Fruit punch $(40.0)^{* *}$ & Soap $(60.0)^{*}$ \\
\hline & & & Gasoline $(92.0)^{*}$ & Rose $(28.0)^{*}$ \\
\hline & & & Strawberry $(16.0)^{*}$ & \\
\hline & $\mathrm{MCS}<\mathrm{CONT}$ & Menthol $(62.0)^{*}$ & & - \\
\hline \multirow{4}{*}{ CC-SIT } & $\mathrm{MCS}>\mathrm{CONT}$ & $-\omega_{-}$ & \multirow{4}{*}{$\begin{array}{l}\text { Rose }(32.0)^{*} \\
\text { Banana }(36.0)^{*}\end{array}$} & \multirow{4}{*}{$\begin{array}{l}\text { Pineapple }(20.0)^{*} \\
\text { Soap }(36.0)^{* *}\end{array}$} \\
\hline & & & & \\
\hline & $\mathrm{MCS}<\mathrm{CONT}$ & Banana $(36.0)^{*}$ & & \\
\hline & & Soap $(60.0)^{*}$ & & \\
\hline
\end{tabular}

( ); prevalence $(\%)$ in larger group. ${ }^{*} p<0.05 .{ }^{* *} p<0.01$.

TABLE 7. Correlation between UPSIT and CC-SIT in MCS and controls regarding scores, numbers of pleasant and unpleasant odors per person

\begin{tabular}{|c|c|c|c|c|c|c|c|c|c|}
\hline \multirow{3}{*}{ Groups } & & & & \multicolumn{6}{|c|}{ Impression } \\
\hline & \multicolumn{3}{|c|}{ Scores } & \multicolumn{3}{|c|}{ Pleasant } & \multicolumn{3}{|c|}{ Unpleasant } \\
\hline & $r$ & $y: a+b x$ & $p$-value $(<)$ & $r$ & $y: a+b x$ & $p$-value $(<)$ & $r$ & $y: a+b x$ & $p$-value $(<)$ \\
\hline $\begin{array}{c}\mathrm{MCS} \\
(n=25)\end{array}$ & 0.62 & $-0.10+0.31 x$ & 0.001 & 0.80 & $0.34+0.32 \mathrm{x}$ & 0.001 & 0.65 & $0.77+0.27 x$ & 0.001 \\
\hline $\begin{array}{c}\text { CONT } \\
(n=50)\end{array}$ & 0.45 & $4.38+0.17 \mathrm{x}$ & 0.001 & 0.73 & $1.70+0.26 \mathrm{x}$ & 0.001 & 0.60 & $0.76+0.20 \mathrm{x}$ & 0.001 \\
\hline
\end{tabular}

found that rhinitis was a predominant complaint. Rhinolaryngoscopic findings were abnormal in all patients: edema, excessive mucus, a cobblestone appearance of the posterior pharynx and base of the tongue, and mucosal injection were observed frequently.

Hummel (1996) investigated whether MCS patients show different responses after exposure to either room air or low concentrations of 2-propanol. Performance of the nasal chemical senses was evaluated by means of chemosensory event-related potentials (CSERP) in response to olfactory $\left(\mathrm{H}_{2} \mathrm{~S}\right)$ and trigeminal $\left(\mathrm{CO}_{2}\right)$ stimuli. The study provided evidence that MCS patients respond to 2-propanol with changes in their chemosensory perception which might increase their susceptibility to environmentally volatile chemicals. Changes in the pattern of event- related potentials are interpreted as possible change in the orientation of cortical generators.

Subjects can acquire somatic symptoms and altered respiratory behavior in response to harmless, but odorous chemical substances, if these odors have been associated with a physiological challenge that originally had caused these symptoms (Van den Berg et al. 1999).

To explore the role of cognitive bias in chemical exposure, Dalton et al. (1997) evaluated whether information about the consequences of exposure to acetone could influence ratings of odor and irritation during exposure and/or the frequency of intensity of reported health symptoms following exposure. The results provide strong evidence that both the perceived odor and cognitive expectations about a chemical can significantly affect how individuals respond to 
it.

While a variety of mechanisms have been proposed for interpretations of negative esthetic response to odors in MCS and the difficulty in evaluation of olfactory function tests, this olfactory test can possibly be used for diagnostic procedures of MCS. The increased number of odors causing unpleasant sensation is included in Cullen's criteria of MCS. The cut-off points of 21 unpleasant odors per person for UPSIT and 6 for CC-SIT are plausible to diagnose MCS despite the low sensitivity of $16 \%$ and $28 \%$, respectively. This low sensitivity with high specificity indicates the usage of this test for the confirmation of MCS in the clinical setting and not for the screening of this condition.

In this study, the ability of odordiscrimination was evaluated by use of UPSIT and CC-SIT. These standardized "scratch and sniff" olfactory tests have several unique features, including amenability to self administration, a means for detecting malingering, and lack of dependence upon complex equipment (Doty et al. 1984). While UPSIT contains 40 odors including unfamiliar odors for other nationalities than the USA and taking $15 \mathrm{~min}-$ utes for test, CC-SIT requiring 5 minutes to complete 12 odorants (Doty et al. 1996). The validity of CCSIT was evaluated in Japan (Furuta 1992).

The percent scores in UPSIT and CC-SIT in this study were almost identical in both MCS and controls. Both UPSIT and CC-SIT indicated larger number of unpleasant odors per person in MCS than in controls. However, the number of pleasant odors per control subject outnumbered that of MCS subjects in only CC-SIT. The numbers of pleasant and unpleasant odors per person by UPSIT and CCSIT correlated significantly. Since MCS subjects usually dislike the exposure to various odors, testing odors should be infrequent and the testing time should be as short as possible. Therefore, CC-SIT is favorable for the evaluation of esthetic odor-response in MCS subjects.
In this study, gender-difference was not marked except for unpleasant odors per MCS subject significantly outnumbering the controls in women but this was not found in men. This finding suggests that women with MCS respond more negatively to odors, although the numbers of subjects were not comparable regarding gender.

Doty et al. (1985) reported that the women of all four ethnic groups outperformed the men in odor identification ability. The studies of Lehrner (1993) on the olfactory function also revealed that women surpass men in their ability to identify odors in both forced-choice and free recall tests. One possible reason for this superiority is that women are more aware of odors than men because women encounter odors more frequently than men due to environmental influences. Henkin (1974) observed that increases in taste, smell and auditory detection acuity and in light touch and two-point discrimination occurred in the follicular phase of the menstrual cycle prior to the midcycle increase in basal body temperature or in plasma LH concentration.

Epidemiological study reveals that women are more susceptible to MCS than men (Fiedler and Kipen 1997). The marked excess in symptom prevalence among females in sick building syndrome was also observed (Stenberg and Wall 1995). Therefore, the susceptibility to environmental illness in women could be attributed to their increased olfactory sensitivity.

In this study, soap made MCS subjects more unpleasant and less pleasant than the controls, while a variety of odors were selected as unpleasant in the MCS group. Gingerbread, on the other hand, was chosen as pleasant in MCS subjects. It should be examined if the odor of gingerbread may alleviate the symptoms of MCS and positively affect the clinical course of MCS though this odor is not familiar to Japanese. Olfactory function tests are thought meaningful for pathophysiology, diagnosis and treatment of MCS. 


\section{Acknowledgments}

This study was supported by Health Science Research Grants from the Ministry of Health, Labor and Welfare and partly supported by the Academic Frontier Project of the Ministry of Education, Culture, Sports, Science and Technology. The authors are grateful to Ms. Yumiko Sugiura and Ms. Yumi Komatsu for their technical assistance.

\section{References}

Bell, I.R., Miller, C.S. \& Schwartz, G.E. (1992) An olfactory-limbic model of multiple chemical sensitivity syndrome: possible relationships to kindling and affective spectrum disorders. Biol. Psychiatry, 32, 218-242.

Caccappolo, E., Kipen, H., Kelly-McNeil, K., Knasko, S., Hamer R.M., Natelson, B. \& Fiedler, N. (2000) Odor perception: multiple chemical sensitivities, chronic fatigue, and asthma. JOEM, 42, 629-638.

Cullen, M.R. (1987) The worker with multiple chemical sensitivities: an overview. Occup. Med. State of the Art Reviews, 2, 655-661.

Dalton, P., Wysocki, C.J., Brody, M.J. \& Lawley, H.J. (1997) The influence of cognitive bias on the perceived odor, irritation and health symptoms from chemical exposure. Int. Arch. Occup. Environ. Health, 69, 407-417.

Doty, R.L., Shaman, P. \& Dann, M. (1984) Development of the University of Pennsylvania Smell Identification Test: a standardized microencapsulated test of olfactory function. Physiology Behav., 32, 489-502.

Doty, R.L., Applebaum, S., Zusho, H. \& Settle, R.G. (1985) Sex differences in odor identification ability: a cross-cultural analysis. Neuropsychologia, 23, 667-672.

Doty, R.L., Deems, D.A., Frye, R.E., Pelberg, R. \& Shapiro, A. (1988) Olfactory sensitivity, nasal resistance, and autonomic function in patients with multiple chemical sensitivities. Arch. Otolaryngol Head Neck Surg., 114, 14221427.

Doty, R.L. (1994) Olfaction and multiple chemical sensitivity. Toxicol. Ind. Health, 10, 359-367.

Doty, R.L., Marcus, A. \& Lee, W.W. (1996) Development of the 12-item Cross-Cultural Smell Identification test (CC-STT). Laryngoscope, 106, 353-356.
Fiedler, N. \& Kipen, H. (1997) Chemical sensitivity: the scientific literature. Environ. Health. Perspect., 105, 409-415.

Furuta, S., Egawa, M., Ozaki, M. \& Ohyama, M. (1992) Clinical application of the Smell Identification Test. J. Otolaryngol. Japan, 95, 1339-1344. (in Japanese with English abstract)

Henkin, R.I. (1974) Sensory changes during the menstral cycle. In: Biorhythms and Human Reproduction, edited by M. Ferin, F. Halberg, R.M. Richaart \& R.L. Vande, Wiele, A. Wiley Biomedical-Health Publication, New York, pp. 277-285.

Hummel, T., Roscher, S., Jaumann, M.P. \& Kobal, G. (1996) Intranasal chemoreception in patients with multiple chemical sensitivities: A double-blind investigation. Regul. Toxicol. Pharmacol., 24, Suppl., 79-86.

Lehrner, J.P. (1993) Gender differences in longterm odor recognition memory: verbal versus sensory influences and the consistency of label use. Chemical Senses, 18, 17-26.

Meggs, J.M. \& Cleveland, C.H. (1993) Rhinolaryngoscopic examination of patients with the multiple chemical sensitivity syndrome. Arch. Environ. Health, 48, 14-18.

Miller, C.S. \& Mitzel, H.C. (1995) Chemical sensitivity attributed to pesticide exposure versus remodeling. Arch. Environ. Health, 50, 119129.

Randolph, T.G. (1970) Domicililary chemical air pollution in the etiology of ecologic mental illness. Int. J. Soc. Psychiatry, 16, 243-265.

Ross, P.M., Whysner, J., Covello, V.T., Kuschner, M., Rifkind, A.B., Sedler, M.J., Trichopoulos, D. \& Williams, G.M. (1999) Olfaction and symptoms in the multiple chemical sensitivities syndrome. Prevetive. Med., 28, 467-480.

Simon, G.E., Daniell, W., Stockbridge, H., Claypoole, K. \& Rosenstock, L. (1993) Immunologic, psychological, and neuropsychological factors in multiple chemical sensitivity. Ann. Int. Med., 19, 97-103.

Stenberg, B. \& Wall, S. (1995) Why do women report 'sick building symptoms' more often than men? Soc. Sci. Med., 40, 491-502.

Tonori, H., Aizawa, Y., Ojima, M., Miyata, M., Ishikawa, S. \& Sakabe, K. (2001) Anxiety and depressive states in multiple chemical sensitivities. Tohoku J. Exp. Med., 193, 115126. 
Van den Berg, O., Stegen, K., Diest, I.V., Raes, C., Stulens, P., Eelen, P., Veulemans, H., Van de Woestijne, K.P. \& Nemery, B. (1999) Acquisition and extinction of somatic symptoms in response to odours: a pavlovian paradigm relevant to multiple chemical sensitivity. Occup. Environ. Med., 56, 295-301. 